\title{
Erratum to: CCR7 and VEGF-C: Molecular Indicator of Lymphatic Metastatic Recurrence in pNO Esophageal Squamous Cell Carcinoma after Ivor-Lewis Esophagectomy?
}

Yong Ming Song, MM, Zhou Wang, MD, Xiang Yan Liu, MD, Wen Peng Jiang, MM, and Mo Shi, MM

Department of Thoracic Surgery, Provincial Hospital Affiliated to Shandong University, Shandong, China

ERRATUM TO: ANN SURG ONCOL (2012) 19:3606-3612

DOI 10.1245/S10434-012-2419-Y

The authors' affiliation should read "Provincial Hospital Affiliated to Shandong University," instead of "Provincial Hospital Affiliated with Shandong University."
Also, the abbreviated given names of the first, third, and fourth authors were incorrectly captured. The correct abbreviations are Song YM, Liu XY, Jiang WP.

The online version of the original article can be found under doi:

10.1245/s10434-012-2419-y.

(C) Society of Surgical Oncology 2012

Published Online: 14 December 2012

Z. Wang, MD

e-mail: wz620226@hotmail.com 